\title{
Biodegradable functional biomaterials exploiting substituted trimethylene carbonates and organocatalytic transesterification
}

\begin{abstract}
Kazuki Fukushima
Biodegradable aliphatic carbonyl polymers, such as polylactides, polylactones and polycarbonates, have been studied for application in a broad range of resorbable medical devices. With progress in diagnostic and therapeutic technologies for an aging society, the demand for diverse and highly developed biodegradable biomaterials has increased. A combination of heterocyclic monomers with functional substituents and complex macromolecular architecture has been proposed as a means to produce multifunctional biodegradable polymers. This review mainly highlights the synthesis and application of poly(trimethylene carbonate) (PTMC) analogs with various substituents derived from 2,2-bis(methylol)propionic acid. In addition, organocatalytic transesterification is discussed as an indispensable tool for further functionalization and sophistication of the PTMC analogs. Metal-free controlled polymerization allows for both the safer production of biomedical devices and the precise formation of complex macromolecular structures. The organocatalytic depolymerization of engineering polyesters has also been exploited to efficiently produce valuable aromatic terephthalamides that, in turn, can be used to extend the functionality of PTMC analogs such as mesogen-like motifs. Finally, the use of supramolecular chemistry for further multi-functionalization and hydration-based improvement of biocompatibility is briefly discussed.
\end{abstract}

Polymer Journal (2016) 48, 1103-1114; doi:10.1038/pj.2016.80; published online 14 September 2016

\section{INTRODUCTION}

The demand for diversified and sophisticated biomaterials in the clinical setting is increasing. For instance, polymeric micelles have been widely studied as a drug-delivery system (DDS) with targeting and stealth functions to peripheral areas and drug encapsulation and release properties. ${ }^{1,2}$ In addition, recent tissue engineering studies have attempted to develop scaffolds with high or multiple functions, including non- or low-fouling, cell adhesive and antithrombotic properties. $^{3-5}$ The polymers used for these applications should be minimally toxic, and the fate of degradation products in the body should be evaluated if the polymers are designed to be degraded under physiological conditions. Poly(lactide)s (PLAs) are the biodegradable polymers most widely used as biomedical materials. ${ }^{6}$ However, the degradation of PLAs induces a drastic decrease in mechanical properties and a surge in local acid concentration that may cause inflammatory reactions. ${ }^{7,8}$ Thus, poly(trimethylene carbonate) (PTMC) has drawn attention as a biodegradable soft material because its degradation generates no organic acids and proceeds by enzymes via surface erosion, enabling the mechanical properties to be maintained for a longer period of time. ${ }^{9}$

As with many aliphatic carbonyl polymers that are biodegradable, including PLAs, poly( $\varepsilon$-caprolactone) and poly( $\beta$-hydroxyalkanoate $) s,{ }^{10-12}$ copolymers, polymer blends and composites based on PTMC have been widely studied to introduce additional functions for expanded applications. However, the introduction of chemical functionalities to those polymer backbones is often more useful for highly functionalized biomaterials. Because synthetic biodegradable polymers are typically obtained by ring-opening polymerization (ROP), the synthesis and ROP of the corresponding cyclic monomers with a functional pendant group have been widely studied. ${ }^{12,13}$ Several analogs of trimethylene carbonate (TMC) have also been developed from substituted 1,3-propanediols and show advantages in the synthesis and handling compared with other substituted heterocyclic monomers. ${ }^{14,15}$ These pendant groups of TMC analogs confer diverse chemical functions to biodegradable polycarbonates.

Functionality is also generated and differentiated by size and shape, particularly for nanomaterials, as is often observed in biological systems such as viruses, enzymes and antibodies. The size and shape of self-assembling nanomaterials depend on the higher order structure, which is regulated by a finely tuned primary molecular structure. Controlled polymerization is considered to be indispensable for building complex macromolecular architectures with finely tuned sequences, molecular weights and end groups. Some organocatalysts were used for the controlled ROP of cyclic esters and carbonates in a variety of studies in the 2000s. ${ }^{16,17}$ A metal-free process has been anticipated for years for the safer production of biomedical materials, particularly those expected to remain in the body. Thus, a combination of TMC analogs and organocatalytic-controlled ROP 

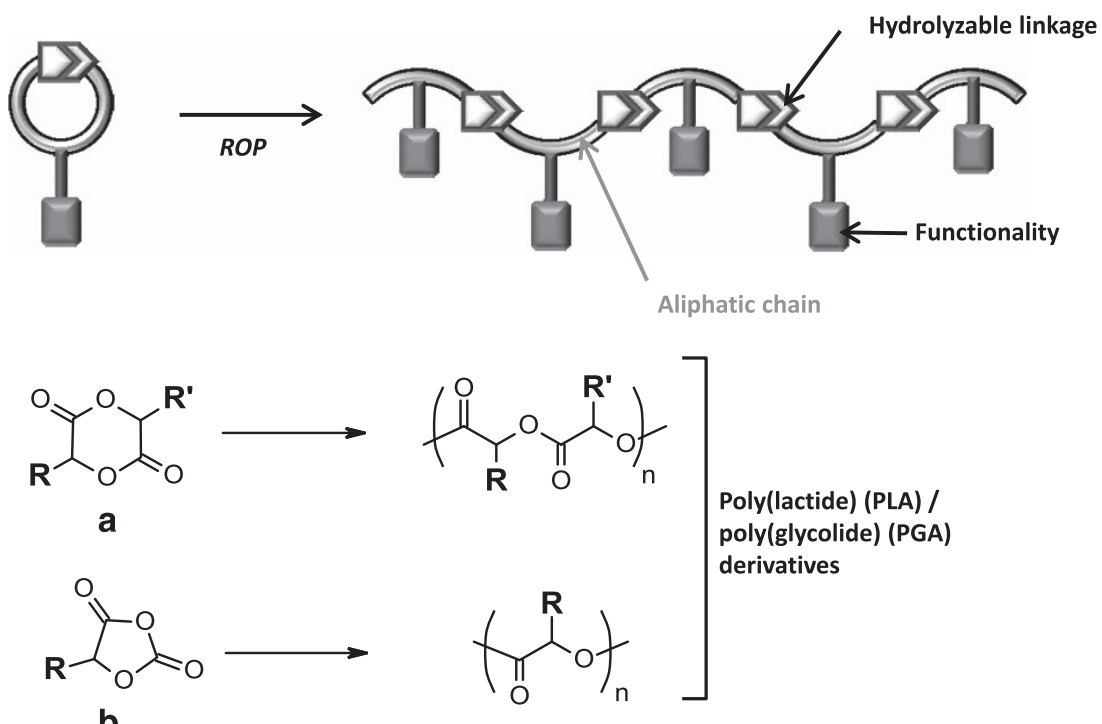

Poly(lactide) (PLA) /

poly(glycolide) (PGA)

derivatives

b<smiles>[R]C1NC(=O)C([R])OC1=O</smiles><smiles>[R]C1NC(=O)OC1=O</smiles><smiles>[R]OC(=O)C(CC(=O)C(C)C)OC(C)(C)C</smiles>

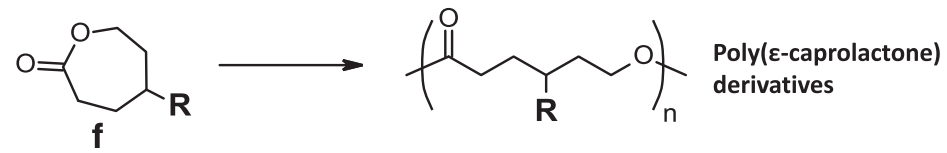

Figure 1 Typical examples of synthetic biodegradable polymers with functional side chains.

would be important for the multi-functionalization of biodegradable biomaterials.

Organocatalysis has revolutionized a wide range of organic reactions to develop useful materials such as asymmetric molecules and drug precursors. ${ }^{18,19}$ Some potent organocatalysts used for ROP can be applied not only in the atom-economic depolymerization of engineering polyesters such as poly(ethylene terephthalate) $(\mathrm{PET})^{20,21}$ but also in the production of building blocks for functional biomaterials using advanced chemical recycling. ${ }^{22,23}$ Organocatalytic transesterification may involve a fusion of the development of biomaterials and green chemistry. Indeed, the author has addressed the development of biodegradable functional biomaterials using TMC analogs and the depolymerization products of PET. ${ }^{24}$ This review focuses on chemically functionalized PTMC analogs from the perspective of synthesis and application in various biomedical devices and describes organocatalysts as powerful and essential tools for producing highly functional biomaterials.

\section{BIODEGRADABLE POLYMERS WITH FUNCTIONAL SIDE CHAINS}

To modify the physical properties of nonfunctional biodegradable polymers such as PLA, poly( $\varepsilon$-caprolactone) and PTMC, copolymerization and polymer blending are typically the first options. For further alteration, the introduction of functional pendant groups on the side chain to the polymer backbone is considered to be an effective strategy. Although chemically functionalized biodegradable polymers are prepared through step-growth approaches, including polycondensation, ${ }^{25,26}$ polyaddition ${ }^{27,28}$ and acyclic diene metathesis, ${ }^{29,30}$ the synthesis and ROP of cyclic monomers with a functional substituent are typically used.

\section{Introduction of FGs to cyclic carbonyl monomers}

The synthesis of functionalized aliphatic carbonyl polymers has been studied first to obtain water-soluble biodegradable polymers with hydroxy, carboxyl and amino side groups as an alternative to 
poly(ethylene glycol) (PEG). ${ }^{31-34}$ Recent studies have focused on the post-modification of reactive pendant groups using dicyclohexyl carbodiimide coupling, ${ }^{35,36}$ alkyne-azide click reaction, ${ }^{37,38}$ Michael addition, ${ }^{39,40}$ Diels-Alder cycloaddition ${ }^{41,42}$ and the thiol-ene(-yne) reaction. ${ }^{43,44}$ As shown in Figure 1, several monomer platforms have been developed: substituted lactide (LA, a) and glycolide (GA, a) ${ }^{45}$ $\alpha$-hydroxy acid O-carboxyanhydride (OCA, b), ${ }^{46}$ morpholine-2, 5-dione (MDO, c) ${ }^{35,47}$ amino acid $N$-carboxyanhydride (NCA, d) ${ }^{48-50}$ $\beta$-malolactonate $(\beta-\mathrm{ML}, \quad \mathbf{e})^{51}$ and substituted $\varepsilon$-caprolactone (CL, f). ${ }^{52,53}$ Functionalized PLAs and poly(glycolide)s are generated by ROP of the substituted LA and GA or decarboxylative ROP of OCA. Similarly, functionalized poly(ester-amide)s, poly(amino acid)s, poly( $\beta$-hydroxybutyrate) and poly( $\varepsilon$-caprolactone $)$ are derived from MDO, NCA, $\beta$-ML and substituted CL, respectively. $\alpha$-Amino acids can be used as a starting material for substituted LA/GA, OCA and MDO, as well as for NCA production, because $\alpha$-hydroxy acids constituting these monomers are derived from the amino acids. ${ }^{46,54,55}$ Therefore, these polymers have been recognized as valuable bio-based biomaterials, although some issues remain to be solved in the synthesis and handling of the monomers.

\section{Poly(trimethylene carbonate) analogs from 2,2-bis(methylol)} propionic acid

TMC analogs with functional substituents have more advantages for the synthesis and properties of the monomers than the cyclic monomers described above. There are several commercially available substituted 1,3-diols that can be used as a starting material and are available at reasonable prices, and the monomers are relatively stable and, thus, are easy to handle. ${ }^{56-59}$ 2,2-Bis(methylol)propionic acid (bis-MPA) is among the most adopted starting material for substituted TMC, so-called MTCs, ${ }^{60}$ because it is a building block of biocompatible dendrimers, ${ }^{61}$ and various functional groups (FGs) can be added through esterification and amidation using a variety of commercially available alcohols and amines to the carboxyl group, as shown in Figure 2. In route A, FGs are installed by Fischer esterification, which limits the available alcohols. ${ }^{62}$ For route C, FGs must be tolerant of acidic conditions to deprotect the acetal intermediate. ${ }^{63}$ Route B, developed by Pratt et al., ${ }^{64}$ is versatile and can therefore accept any type of FG, because the FGs are installed to a common carboxylic acid precursor (MTC-OH) in the final stage. Sanders et al. ${ }^{65}$ then discovered a breakthrough in MTC synthesis in which bis (pentafluorophenyl)carbonate provides an MTC with a pentafluorophenyl ester in one step from bis-MPA (route D) ${ }^{65}$ In addition, the pentafluorophenyl ester is an activated ester, allowing easy substitution with alcohols containing FG. ${ }^{6}$ However, bis(pentafluorophenyl) carbonate is costly, limiting its widespread use. A new method was recently developed to obtain $\mathrm{MTC}-\mathrm{OH}$ through a simpler route than route $\mathrm{B}$ and without the costly reagent used in route D. ${ }^{67,68}$ Additional details regarding TMC analogs derived from other starting materials can be found elsewhere. ${ }^{69}$

\section{ORGANOCATALYSTS FOR TRANSESTERIFICATION}

In polymer chemistry, semiconductor fabrication involves block copolymer self-assembly ${ }^{70}$ and the metal-free synthesis of masking materials because of concerns regarding residual metals derived from polymerization catalysts deteriorating the semiconducting properties. Stemming from this trend, in the early 2000s, Hedrick and Waymouth reported various organocatalysts for the transesterification-based ROP of cyclic carbonyl monomers. ${ }^{71,72}$ Typical catalysts are summarized in Figure 3. Since then, various organometallic catalysts have been developed for the ROP of LAs. ${ }^{11,73}$ Stannous octanoate (or 2-ethylhexanoate) is among the most popular and only compound approved by the FDA. Aluminum alkoxides are effective for controlled or/and living polymerization of LAs and cyclic esters ${ }^{74}$ as well as stereoregular polymerization. ${ }^{75,76}$ A recent report by Mespouille demonstrated the low toxicity of several organocatalysts, supporting the advantage of the metal-free production of polymeric biomaterials. ${ }^{77}$

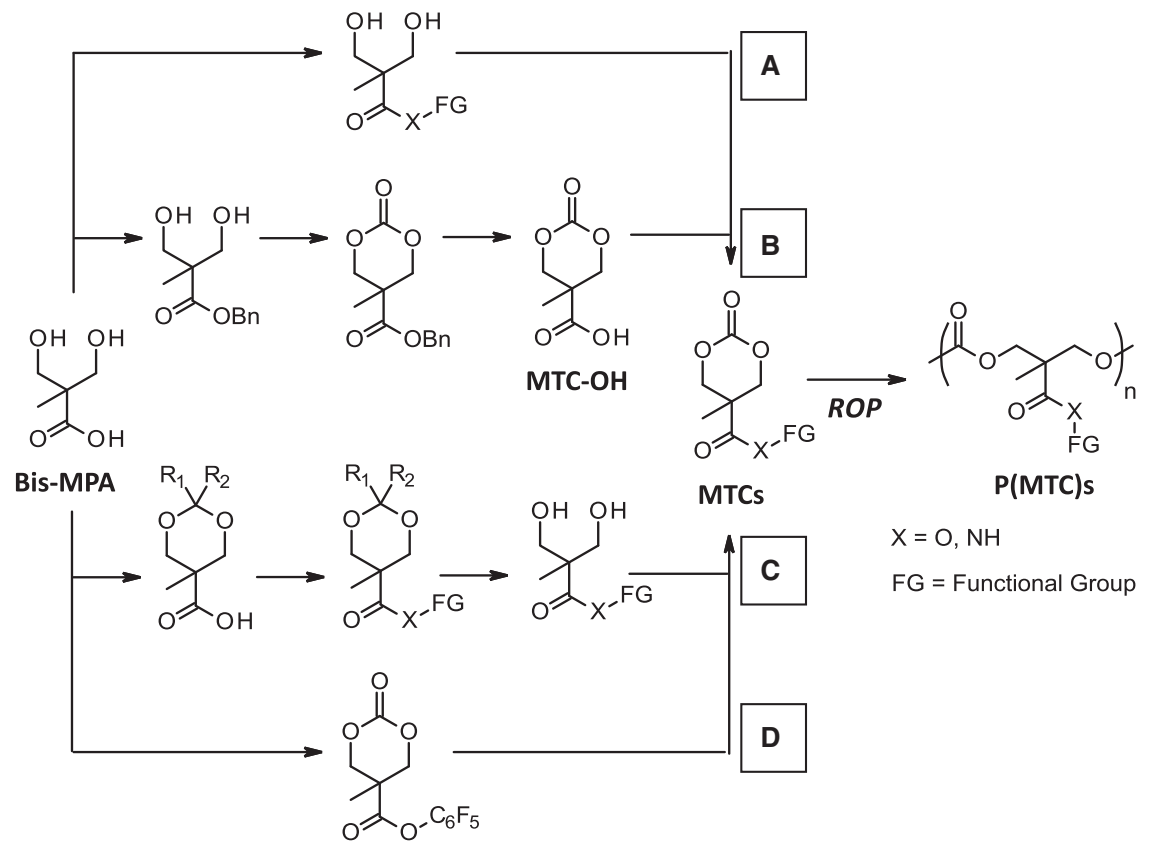

Figure 2 Different synthetic pathways for MTCs with functional groups. 
a

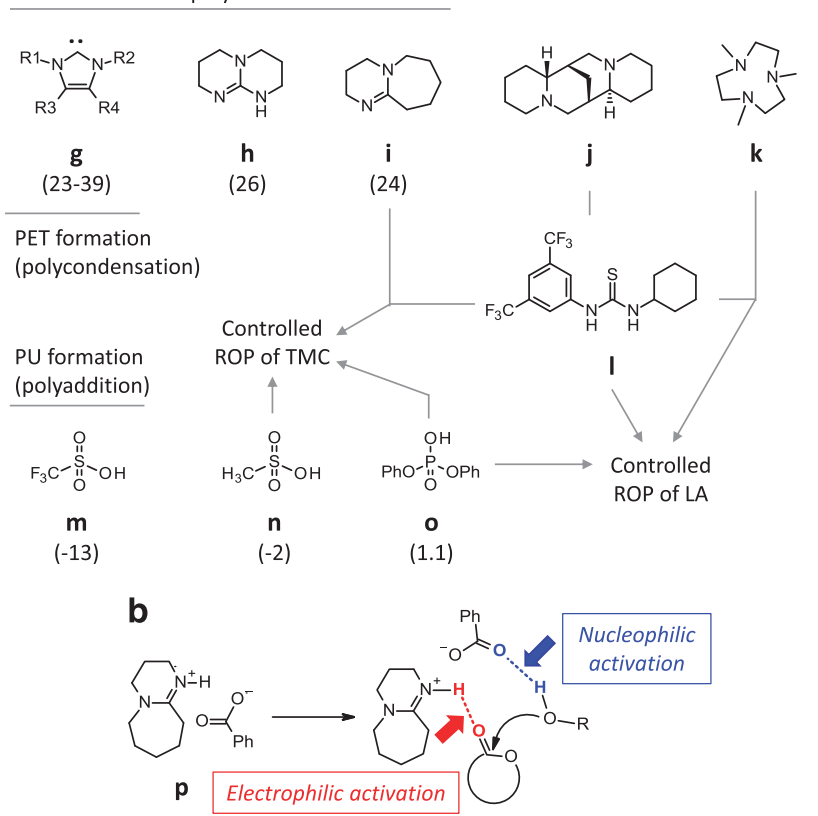

Figure 3 (a) Various organocatalysts used for polymerization/depolymerization through transesterification. The numbers in parentheses denote $\mathrm{pKa}$ values. (b) DBU-benzoic acid salt catalyst and its $\mathrm{H}$-bonding mechanism.

\section{Depolymerization to produce valuable building blocks for functional biomaterials}

The organocatalysts discovered in the 2000s are mostly basic ( $\mathbf{g}-\mathbf{h})$, and some quasi-anionic mechanisms were proposed: nucleophilic, activated monomer and supramolecular hydrogen-bonding (H-bonding) activation. ${ }^{78,79}$ Acidic organocatalysts ( $\left.\mathbf{m}-\mathbf{- o}\right)$ were found to be more effective than basic catalysts for the ROP of CL and MTCs with an amide pendant group. ${ }^{80-82}$ The catalytic activity is associated with the basicity or acidity of the catalysts. Thus, $\mathrm{pKa}$ is often used as a parameter for estimating catalytic activity (see Figure 3). ${ }^{82-84}$ $\mathrm{N}$-heterocyclic carbenes (NHCs, g) and 1,5,7-triazabicyclo[4.4.0] dec-5-ene (TBD, h) actively mediate the ROP of LAs, completing the reaction in seconds with a turnover frequency (TOF) of $18-80 s^{-1}{ }^{85,86}$ However, it is difficult for these potent catalysts to control the transesterification occurring in the late stage of ROP, resulting in broadening of the molar mass distribution $\left(\oplus_{M}\right)$ of the resultant polymers.

The powerful efficacy of these catalysts for transesterification was extended to the depolymerization of PET for chemical recycling (Figure 4). ${ }^{20,87}$ 1,8-Diaza[5.4.0]bicycloundec-7-ene (DBU, i) was found to be the most effective for glycolysis, ${ }^{87}$ and TBD was the most effective for other alcoholysis and aminolysis reactions of PET. ${ }^{22}$ Their catalytic activities are comparable to or greater than those of organometallic catalysts. These 'superbases' are commercially available, easy to handle on the bench and reusable, which is preferable for large-scale recycling. Furthermore, their potent activity allows for amidation by arylamines whose nucleophilicity is insufficient for amidation. $^{22}$ The resulting aromatic terephthalamides can be used as valuable building blocks for tough polymers and mesogen-like supramolecular assembling motifs such as $\mathbf{q}$ (Figure 4), yielding good antimicrobials 8 and $\mathbf{9}$ as described below. ${ }^{23,24}$ This is a typical example of creating useful biomaterials from waste plastics by connecting biomaterials and green chemistry via organocatalysis. Some NHCs were proven to be effective in polycondensation to yield PET. ${ }^{88}$

\section{Hydrogen-bonding activation}

For controlled and living polymerization, it is crucial that the catalysis shows end-group fidelity and a narrow $\bigoplus_{\mathrm{M}}$ at the late or post-stage of ROP. Some catalysts known as 'supramolecular catalysts' allow for controlled polymerization with mild activation and thereby the formation of complex architectures such as Y- and H-shapes, comb-block, brush and dendritic star. ${ }^{89,90}$ For these catalysts, H-bonding activation has been proposed; ${ }^{16,91}$ Lewis acids such as thiourea (l) and perfluoroalcohol ${ }^{92}$ activate the carbonyl oxygen $(\mathrm{C}=\mathrm{O})$ of monomers, while Lewis bases such as $(-)$-sparteine $(\mathbf{j})$ and 1,4,7-trimethyl-1,4,7-triazacyclononane (TACN, k) activate the hydroxyl oxygen $(\mathrm{OH})$ of alcohol initiators. Thiourea has been shown to preferentially activate cyclic esters rather than linear esters. ${ }^{91}$ In this manner, weak double activation and selective activation can suppress adverse transesterification, leading to controlled polymerization. Supramolecular organocatalysts confer another benefit on the ROP of TMC conducted under ambient conditions; the decarboxylation side reaction that often occurs during metal-catalyzed bulk polymerization is avoided..$^{93}$ Indeed, owing to the benefits of these catalysts, polymers of MTCs can be obtained with regulated molecular weights and narrow distributions and can maintain a finely tuned complex architecture in some cases.

H-bonding activation has been proposed for $\mathrm{TBD},{ }^{94}$ sulfonic acids $(\mathbf{m}, \mathbf{n})^{82}$ and diphenyl phosphate $(\mathbf{o})^{95}$ that have two activation sites; therefore, their activation is known as dual activation. The depolymerization of PET is also thought to proceed through an $\mathrm{H}$-bonding activation mechanism where the by-product ethylene glycol serves as a co-catalyst. ${ }^{20}$ Sulfonic acids were recently found to be effective for the polyaddition of diols and diisocyanates via dual H-bonding activation to form polyurethanes with high molecular weight and a narrow $\bigoplus_{\mathrm{M}}$ by Sardon et al. ${ }^{96-98}$

$\mathrm{DBU}$ is an overactive catalyst for the ROP of LAs. Coady et al. ${ }^{17}$ proved that a 1:1 complex with benzoic acid (p, Figure 3) remains sufficiently active to promote the ROP of L-lactide (LLA) with a $\bigoplus_{\mathrm{M}}$ maintained below 1.10. A computational study indicated that the activators of initiators and monomers are the conjugate acid and base in the form of an ion pair, even in solvents with high dielectric constants such as ethylene glycol. ${ }^{87}$ This result suggests that the salt catalyst enables controlled polymerization in polar solvents such as tetrahydrofuran (THF), N, N-dimethylformamide (DMF) and dimethyl sulfoxide, which mitigate and disable conventional supramolecular catalysts. In fact, the salt catalyst was useful for ROP using the terephthalamide-based diol initiators $\mathbf{q}$ and their analogs, which dissolve only in DMF and dimethyl sulfoxide.

\section{APPLICATIONS OF FUNCTIONALIZED POLY(TRIMETHYLENE CARBONATE)S}

Because of the diversity of the FGs to be added and the advantages of synthesis, many types of poly(MTC)s (P(MTC)s) have been developed for application in a broad range of biomaterials. ${ }^{69}$ Currently, most $\mathrm{P}(\mathrm{MTC})$ s are used in solution applications such as drug delivery, 2,99 hydrogels ${ }^{38,100}$ and antimicrobials. ${ }^{101,102}$ For instance, the MTC platform, which is free from limitations of the side groups, enables the introduction of complexed structures such as sugar, ${ }^{103}$ guanidine $\mathrm{e}^{104,105}$ and phenylboronic acid ${ }^{106}$ for applications in tumor targeting, cell-penetrating molecular transporters and insulin delivery, respectively. This section highlights the applications of $\mathrm{P}(\mathrm{MTC}) \mathrm{s}$ exploiting the side chains as chemically functional moieties and a building block to forming complex architectures. Next, the development of other functions based on architecture and 


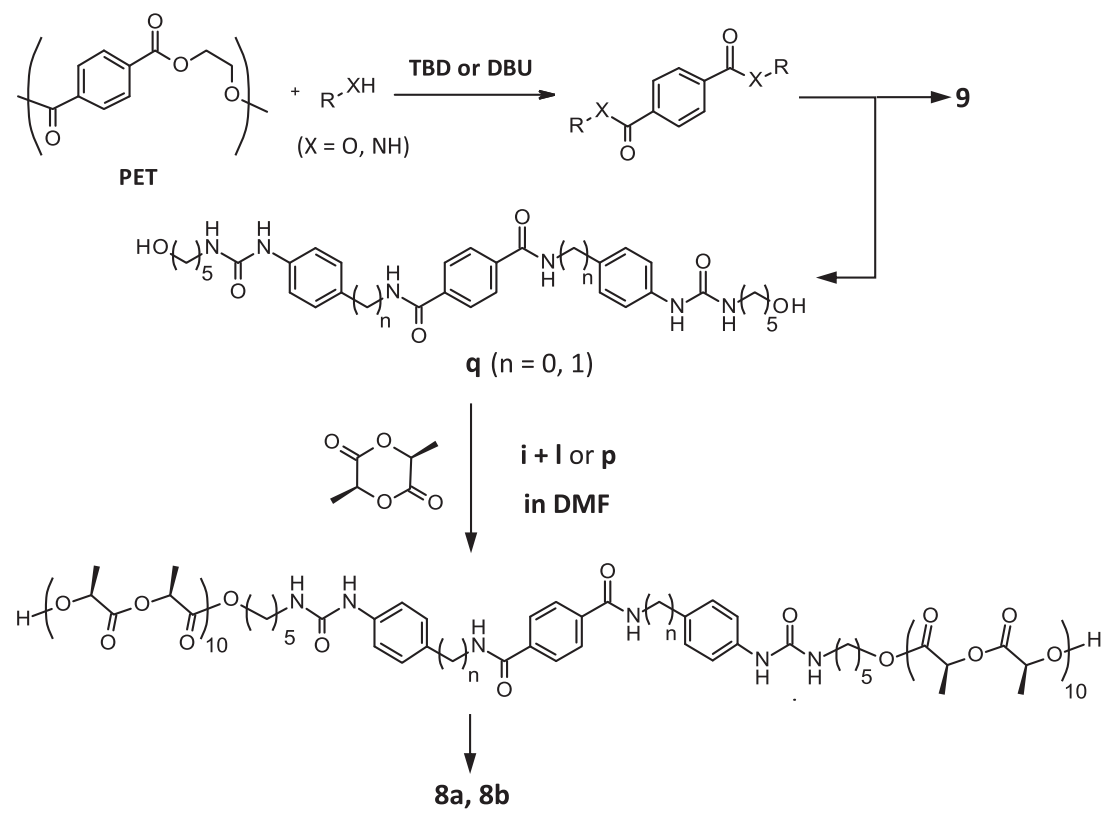

Figure 4 Formation of valuable terephthalamide building blocks for functional biomaterials through organocatalytic depolymerization of PET.

supramolecular chemistry are presented. Finally, the potential of $\mathrm{P}$ (MTC)s as biocompatible materials is discussed.

\section{Drug delivery}

Polymeric micelles based on biodegradable amphiphilic block copolymers such as PEG- $b$-PLA have been widely studied as drug-delivery vehicles, particularly for the therapies of malignant neoplasms and diabetes. Practical DDS must meet several requirements to mitigate adverse effects and increase therapeutic efficiency: the selectivity of target cells, controlled encapsulation and release of drugs, and serum stability. ${ }^{2,107}$ Moreover, polymeric micelles should remain aggregated under high dilution conditions such as those in the blood stream. The stability of polymeric micelles depends on the cohesive force of the micelle core, which mainly relies on hydrophobic interactions. However, simply increasing the composition of hydrophobic segments conflicts with the solubility in water. Stereocomplexation ${ }^{108}$ and H-bonding have been focused on as electrostatic neutral non-covalent interactions for enhancing the aggregation force in the hydrophobic micelle core.

Stereocomplexation is a van der Waals interaction between poly(L-lactide) (PLLA) and poly(D-lactide) (PDLA). ${ }^{109}$ Mixed micelles composed of $\mathrm{PEG}_{5 \mathrm{k}}-b$-PLLA $2 \mathrm{k}$ and $\mathrm{PEG}_{5 \mathrm{k}}-b-\mathrm{PDLA}_{2 \mathrm{k}}$ show a lower critical micelle concentration (CMC: $15 \mathrm{mgl}^{-1}$ ), which is a parameter to evaluate aggregation force, than individual micelles $\left(25 \mathrm{mg} \mathrm{l}^{-1}\right) .^{110}$ For further improvement, comb-block (1b) and mikto-arm block (2) polymers comprising PEG and PLLA and/or PDLA were synthesized using the MTC platform (Figure 5). ${ }^{110,111}$ An MTC with 2-(tetrahydro-2H-pyran-2-yloxy)ethyl ester serves as a building block for initiating the ROP of LLA or D-lactide (DLA) after ROP by monomethoxy PEG-OH $\mathrm{H}_{5 \mathrm{k}}$ and subsequent deprotection of the tetrahydropyranyl group. The resulting hydrophobic segments consist of 10 MTC units with 3-4 PLA arms with a degree of polymerization of 10. The amphiphilic comb-block copolymers $\mathbf{1 b}$ form narrowly dispersed spherical micelles with a diameter of approximately $30 \mathrm{~nm}$ (PDI 0.12). The CMCs of the micelles are $1.0 \mathrm{mgl}^{-1}$ for $\mathrm{L}^{-}$or D-isomer alone and $0.5 \mathrm{mg} \mathrm{l}^{-1}$ for the stereocomplexed mixture. ${ }^{111}$
Such low CMC values arise from the effects of both entangled PLA brushes and stereocomplexation in the micelle core.

The mikto-arm polymer $\mathbf{2}$ is obtained from a PEGylated MTC as a latent macroinitiator for two ROPs of LAs. The mikto-arm can be composed of one hydrophilic PEG (5k) and two hydrophobic PLAs ( $2 \mathrm{k}$ each), whose combination includes two PLLA, two PDLA, and PLLA and PDLA (mikto-arm stereoblock). Spherical micelles with diameters of approximately $30 \mathrm{~nm}$ (PDI $\sim 0.13$ ) are formed with CMCs of 20,15 and $10 \mathrm{mgl}^{-1}$ for PEG-(PLLA) $)_{2}$ or PEG-(PDLA) stereoblock (PEG-PLLA-PDLA), and the stereomixture of PEG-(PLLA $)_{2}$ and PEG-(PDLA $)_{2}$, respectively, indicating the effect of stereocomplexation. Interestingly, the stereomixture and stereoblock micelles show higher loading (10-12 wt\%) and slower in vitro release profiles of paclitaxel than PEG-(PLLA $)_{2}$ micelles. ${ }^{110}$

Urea-functionalized $\mathrm{P}(\mathrm{MTC})\left(M_{\mathrm{n}} \sim 3 \mathrm{k}\right)$ showed similar functions in the form of diblock copolymers with PEG (5k), lowering the CMC by $2.8 \mathrm{mg} \mathrm{l}^{-1}$ and enhancing the drug loading of doxorubicin (Dox) by up to $10 \mathrm{wt} \%$, compared with the control polymer with no urea side chains $(x=0)$ : $\mathrm{CMC}=11.2 \mathrm{mg} \mathrm{l}^{-1}$, Dox loading $6.9 \mathrm{wt} \%$ (Figures 5 and 1a). ${ }^{112,113}$ In this system, urea hydrogen bonding enhances the interactions between not only hydrophobic segments but also the hydrophobic segment and Dox. Urea-functionalized P(MTC) was further investigated to improve the drug encapsulation and release properties by combining carboxy functionalized P(MTC). ${ }^{114-116}$

\section{Cationic polymers}

Cationic polymers show antimicrobial properties because the positive charges serve to electrostatically interact with negatively charged bacterial cell membranes, leading to bacterial lysis. ${ }^{117,118}$ Similarly, the cationic polymers can form polyplexes with negatively charged genes for gene delivery. ${ }^{119}$ Cationic $\mathrm{P}(\mathrm{MTC}) \mathrm{3}$ and $\mathbf{4}$ (Figure 6) are prepared by the ROP of haloalkyl MTCs followed by quaternization with tertiary amines such as trimethylamine and $N, N, N^{\prime}$, $N^{\prime}$-tetramethylethylenediamine. ${ }^{120,121}$

Given the differences in polymerizability between TMC and MTCs, ${ }^{64}$ $\mathrm{P}$ (MTC) 3 can be obtained in one step in which blocky statistical sequences are more likely to be formed. ${ }^{120} \mathrm{P}$ (MTC) 3 has shown high 


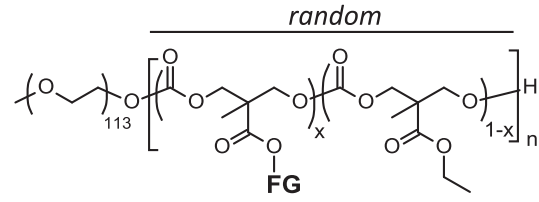

1

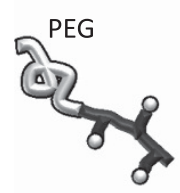

P(MTC)

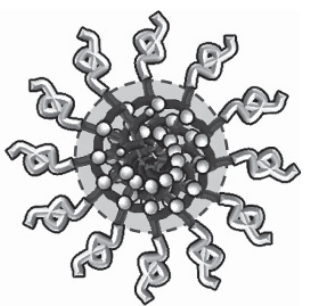

1a: $F G=\left.\overbrace{O}^{N}\right|^{N_{-P h}} \quad$... enhanced loading of Dox

$x=0.2-0.4$

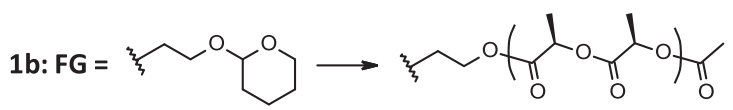

$x=0.3-0.4$

or

... comb-block polymers

Stereocomplexed micelles (lowering CMC)

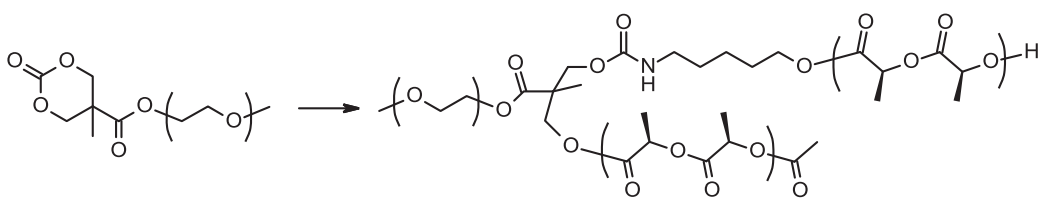

2

... mikto-arm polymers

Figure 5 DDS applications of P(MTC)s capable of stereocomplexation and hydrogen bonding.

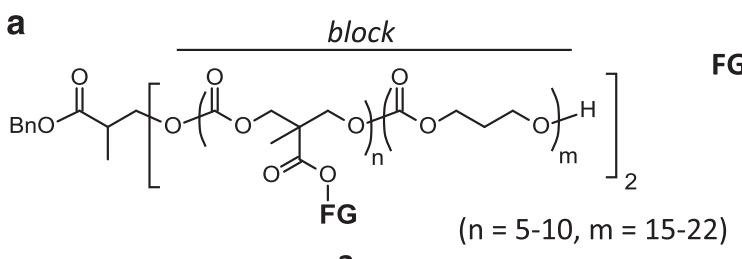

3
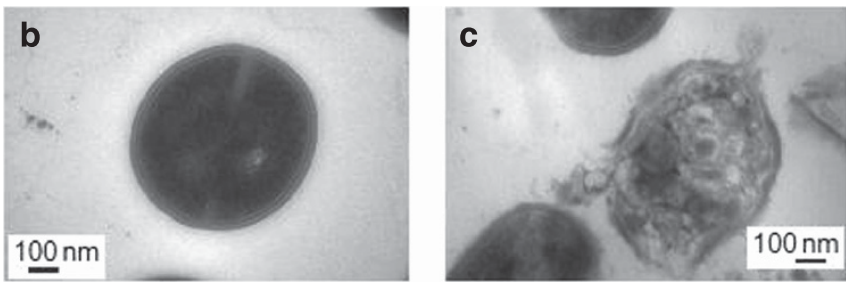

d

random<smiles>[Y]C(C)(C)OCC(COC(=O)OCC)(COC(=O)OCC(C)(COC(=O)OCC(C)(C)C(=O)OCc1ccccc1)C(=O)OF)C(=O)OCC</smiles>

4

$(x=0.5-1.0)$
$F G=$

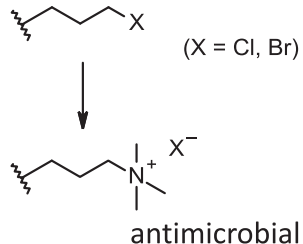

Figure 6 Cationic P(MTC)s for antimicrobial and gene delivery applications. (a, d) Polymer structures. Transmission electron microscope (TEM) images of methicillin-resistant Staphylococcus aureus before (b) and after (c) treatment with 3, reprinted from Nederberg et al. ${ }^{120}$

efficacy in the growth inhibition of several Gram-positive bacteria and fungi, including Bacillus subtilis, Staphylococcus aureus, methicillinresistant Staphylococcus aureus, Enterococcus faecalis and Cryptococcus neoformans, with minimum inhibitory concentrations of 4.3, 7.5, 6.0, 10.8 and $10.8 \mu \mathrm{M}$, respectively. As shown in Figure $6 \mathrm{~b}$ and c, P(MTC) 3 physically disrupts the bacterial cell membrane, suggesting the capability to prevent drug resistance similarly to antimicrobial peptides. ${ }^{122}$ Recent studies have reported several analogs to acquire a broader antimicrobial spectrum that encompasses Gram-positive/negative bacteria, fungi and yeasts while retaining minimal toxicity. ${ }^{101,123,124}$ 
a

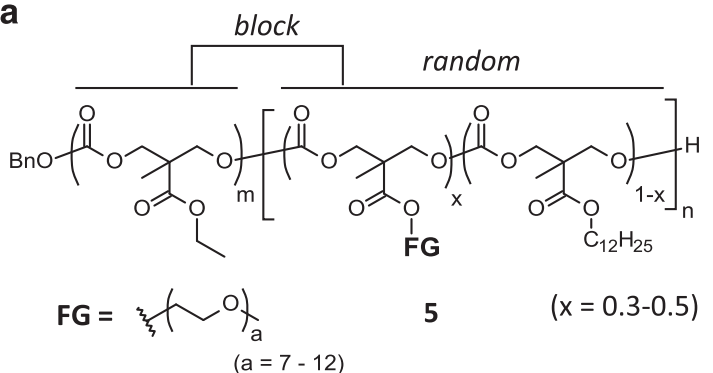

$(a=7-12)$ b

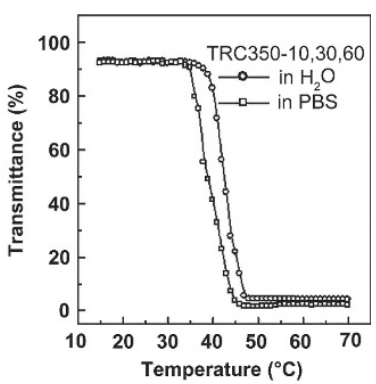

C

block

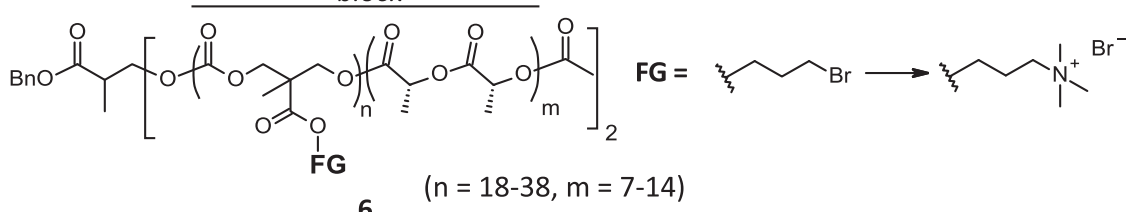
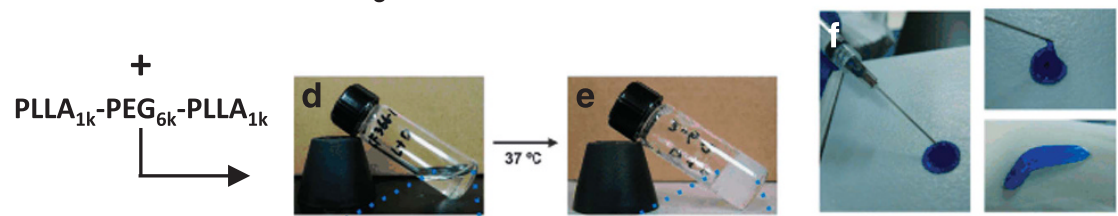

Figure 7 Thermoresponsive P(MTC)s. (a, c) Polymer structures. (b) Transmittance change in aqueous solution of $\mathbf{5}$ as a function of temperature, reprinted from Kim et al. ${ }^{136}$ Photos of the stereocomplexed micellar solution below (d) and above lower critical solution temperature (LCST) (e). Shear-thinning properties of gels containing $\mathbf{6}$. (f) reprinted from Li et al. 138

P(MTC) 4 shows better performance than the conventional chemical gene vector poly(ethylene imine) (PEI) with respect to the formation of compact polyplexes less than $100 \mathrm{~nm}$ for better endocytosis and cell viability. ${ }^{121} \mathrm{P}$ (MTC) 4 also shows higher in vitro gene expression for some tumor cell lines than PEI, which has been presumably attributed to the proton sponge effect ${ }^{125}$ by the tertiary amine at the side chain. Neither cationic P(MTC) exhibits significant toxicity to mammalian cells and is a critical property for materials injected into the body.

\section{Stimuli-responsive polymers}

Stimuli-responsive properties are often applied in DDS as an optional tool for controlling drug release and carrier motion. ${ }^{126,127}$ The use of different stimuli has been proposed, including heat, ${ }^{128} \mathrm{pH},{ }^{129,130}$ light ${ }^{126,131}$ and sugars. ${ }^{132}$ Thermoresponsive polymers such as poly ( $N$-isopropylacrylamide) (PNIPAAM) have been widely studied for injectable and topical drug delivery. They are typically designed to transform sol to gel upon thermal stimulation at a lower critical solution temperature near body temperature. PNIPAAM is not degradable, and concerns exist regarding its biocompatibility. Inspired by the studies of Lutz et al. ${ }^{133,134}$ and Baker and co-workers, ${ }^{37,135}$ $\mathrm{P}$ (MTC) 5 (Figure 7) with short PEG $\left(M_{\mathrm{n}}\right.$ 350-550) and long alkyl branches has been designed to show lower critical solution temperature near body temperature (Figure 7b). ${ }^{136}$ A short segment of $\mathrm{P}(\mathrm{MTC})$ containing an ethyl ester as a hydrophobic block plays an important role in tuning the lower critical solution temperature to allow the $\mathrm{P}(\mathrm{MTC}) \mathbf{5}$ to form micelles. The hydrophilic corona comprises a random sequence of MTCs with short PEG and C12 alkyl chains to regulate the (de)hydration of the corona. Above the lower critical solution temperature, the micelles collapse to accelerate the release of the encapsulated drug, demonstrating the thermoresponsive switching of drug release.
Similar thermoresponsive physical gelation is observed in stereocomplexed mixtures of triblock copolymers comprising a central PEG block and peripheral PLAs. ${ }^{137}$ Thermoresponsive antimicrobial gel (Figure $7 \mathrm{~d}$ and e) can be derived from triblock copolymers of PLAs and cationic $\mathrm{P}(\mathrm{MTC})$ as a hydrophilic central block rather than PEG (6, Figure 7c). ${ }^{138}$ Interestingly, the cationic $\mathrm{P}(\mathrm{MTC})$ and its block copolymers alone have never exhibited antimicrobial activity against Gram-negative bacteria such as Escherichia coli, while the stereocomplexed hydrogels containing the cationic P(MTC) significantly inhibited bacterial growth as well as biofilm formation that is a cause of drug resistance. Because of the high hydrophilicity of cationic $\mathrm{P}(\mathrm{MTC})$, the hydrogels show shear-thinning properties (Figure 7f), enabling direct injection by syringes and needles for topical antiinfectious treatment and coating into various body cavities.

Thiol-disulfide exchange reactions have also gained attention as a trigger for cargo release under reductive conditions. ${ }^{139}$ As a model case, P(MTC) with disulfide-linked PLLA or PTMC grafts have been recently developed, and it was successfully demonstrated that the grafts were detachable in the presence of a reductive reagent 1,4-dithiothreitol. ${ }^{140}$ This result demonstrates the feasibility of the fine control of macromolecular architecture using the organocatalytic ROP and reduction-responsive drug release in the $\mathrm{P}(\mathrm{MTC})$ platform. Thus, including the thermal responsive system, these $\mathrm{P}(\mathrm{MTC}) \mathrm{s}$ are promising as stimuli-responsive biodegradable polymers with higher durability than similar PLA analogs because of the high stability of the PTMC backbone in an aqueous environment.

\section{Combination with supramolecular chemistry}

The nanostructure shapes are often important for the in vivo behavior of nanomaterials for DDS and antimicrobials. ${ }^{141,142}$ However, few studies have focused on the transformation of the self-assembling nanostructure constituted by amphiphilic block copolymers such as 
a<smiles>CC(OC(=O)C(C)C(C)(C)C)C(=O)Cc1ccc(C(=O)NCc2ccc(CNC(=S)NC(C)(C)COC(C)(C)C)cc2)cc1</smiles>

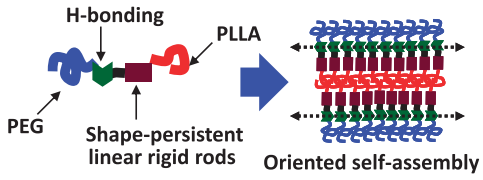

b

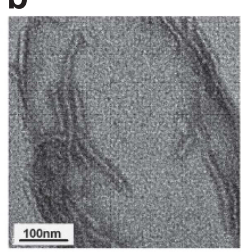

d

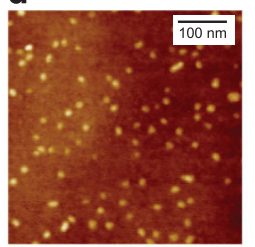

C

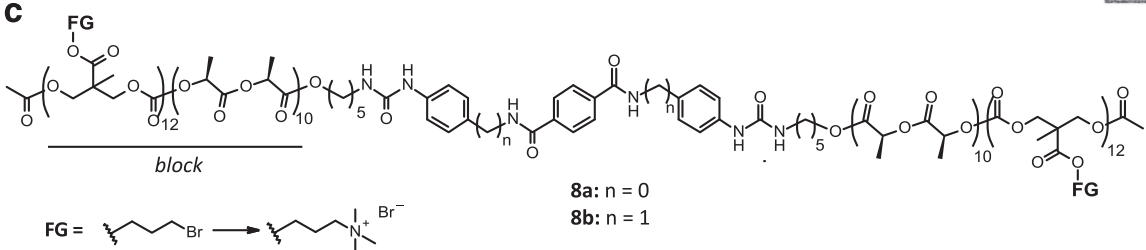

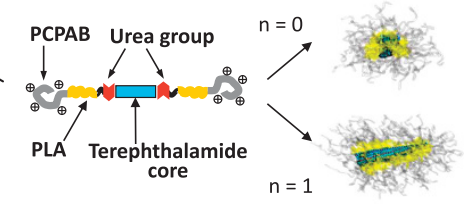

g

$\mathbf{f}$

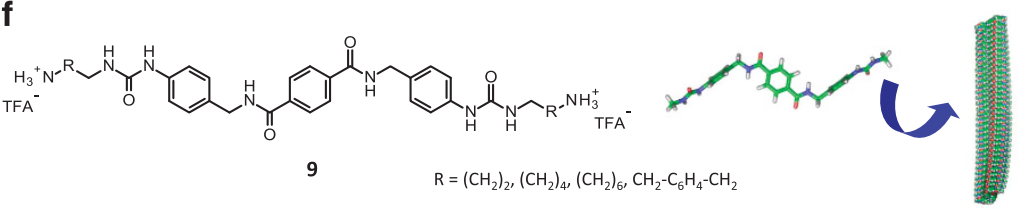

e
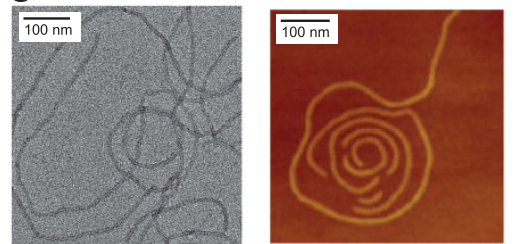

Figure 8 Supramolecular assemblies of amphiphilic block copolymers with rigid hydrogen bonding motifs at the block junction. (a, c, f) Chemical structures. (b) TEM image of nanotubes formed by 7, reprinted from Kim et al. ${ }^{143}$ Atomic force microscope (AFM) images of nanostructure formed by $8 \mathbf{a}$ (d) and $8 \mathbf{b}$ (e), reprinted from Fukushima et al. ${ }^{24}$ (g) TEM image of nanofibers obtained from 9, reprinted from Fukushima et al. ${ }^{23}$

PEG-b-PLLA, which generally form spherical micelles. The formation of block copolymer nanotubes was first achieved by introducing a rigid hydrogen-bonding motif at the block junction of PEG- $b$-PLLA to induce oriented self-assembly (Figure $8 \mathrm{a}$ and b). ${ }^{143}$

This motivated the extension of the oriented self-assembly technique to functional polymers such as antimicrobial cationic $\mathrm{P}(\mathrm{MTC})$ s using similar core structures produced by organocatalytic amidation of PET as described above (Figure 4). ${ }^{22}$ The triblock-like copolymer 8 (Figure 8c) was synthesized from terephthalamide-based diols $\mathbf{q}$ to initiate the ROP of LLA and subsequently elongate the peripheral cationic $\mathrm{P}(\mathrm{MTC}){ }^{24}$ The block copolymer $\mathbf{8 b}$ readily dissolved in water and showed a high-aspect ratio of fibrous nanostructure (Figure 8e). Additional studies have examined the effect of a subtle difference in the terephthalamide cores ( $n=0$ vs 1$)$ and shape effect on the antimicrobial activities. Copolymer $\mathbf{8 a}$ forms uniform spherical aggregates, unlike $\mathbf{8 b}$. A computational study revealed that the core structure of $\mathbf{8} \mathbf{b}$ is more favorable for proper bending to achieve the maximum benefits of hydrogen bonding and $\pi-\pi$ stacking than that of $\mathbf{8 a}$, which cannot sufficiently bend for the anisotropic growth of polymer assembly, resulting in a spherical shape. Moreover, fibrous $\mathbf{8 b}$ exhibits efficiency against Candida albicans, while spherical 8a did not inhibit the fungal growth, supporting the effect of shape on antibacterial activity. Similarly, compound 9 (Figure $8 \mathrm{f}$ ), which is a derivative of $\mathbf{8 b}$ that conjugates no polymers, was found to be effective against $C$. albicans only in the form of fibrous supramolecular assembly (Figure $8 \mathrm{~g}$ ). ${ }^{23}$

\section{Biocompatibility}

Biocompatibility is the most critical characteristic of biomaterials. This term involves many aspects; thus, the definition should be clarified for each target application. Cell viability is often evaluated for the polymers employed in DDS and scaffold materials to verify the low toxicity of the polymers. For scaffold materials, cell proliferation behavior and cellular functions also provide information regarding cytotoxicity. Serum stability, which is related to blood compatibility, is also important for DDS polymers because the vehicles should be inactive in the blood, not self-aggregate or aggregate with proteins, and not activate complements and blood cells.

Most P(MTC)s described above show good cell viability because of the PEGylated surface for micellar products. By contrast, it is surprising that cationic $\mathrm{P}(\mathrm{MTC}) \mathrm{s}$ show minimal hemolytic property, ${ }^{24,120}$ although cationic polymers are typically considered to be toxic. It has been acknowledged that the interactions between materials and cells are regulated by hydration at the interface. ${ }^{144}$ The relationships between hydration and surface properties in specific platelet adhesion have been examined for PTMC, poly $(\delta$-valerolactone $)$, poly( $\varepsilon$-caprolactone $)$ and poly( $p$-dioxanone $).{ }^{145}$ Although platelets adhered to all four polymers, the adhesion level was significantly lower than that of PET as a control. All aliphatic polymers show slightly greater hydrophilic surfaces and equilibrium water content than PET, contributing to better compatibility with platelets, although the levels are higher than those for antithrombotic materials. Interestingly, PTMC only showed a substantial decrease in platelet adhesion upon hydration, indicating its unique hydration behavior at the interface. The PTMC framework may be favorable for interfacial hydration to improve the compatibility with blood cells, which may also explain the very low hemolytic property of a series of cationic $\mathrm{P}(\mathrm{MTC}) \mathrm{s}$. The author is further extending this idea with respect to the potential biocompatibility of aliphatic carbonyl polymers to develop biodegradable polymers with high blood compatibility involving the 'intermediate water' concept. ${ }^{67,146,147}$

\section{CONCLUSION}

Advances in emerging fields such as nanomedicine and regenerative medicine have expanded the demands and scope of application for biodegradable polymers. The production of highly multifunctional biodegradable polymers may become more pragmatic as advances are made in the development of monomer platforms with good accessibility and versatility such as MTCs. In particular, applications in bulk materials such as scaffolds and artificial organs should be further 
explored, including simple and cost-effective synthesis for the mass production of both monomers and polymers, control and balance of mechanical properties and degradability, and suitable processing techniques. Additionally, safer organocatalysts should be further investigated for use in bulk polymerization as applied in the efficient chemical recycling of PET. Furthermore, a combination of selfassembly and supramolecular chemistry may open new frontiers for applications other than drug delivery and antimicrobials, exploiting more practical biomimetics with respect to the hierarchical bottom-up nature, biodegradability and biocompatibility of nano-biomaterials.

\section{CONFLICT OF INTEREST}

The authors declare no conflict of interest.

\section{ACKNOWLEDGEMENTS}

This study was financially supported by a Grant-in-Aid for Scientific Research on Innovative Areas 'Molecular Robotics'(\#24104005) of The Ministry of Education, Culture, Sports, Science, and Technology (MEXT), JSPS Grant-in-Aid for Young Scientists (B) \#25870078, and the Takeda Science Foundation.

1 Wiradharma, N., Zhang, Y., Venkataraman, S., Hedrick, J. L. \& Yang, Y. Y. Selfassembled polymer nanostructures for delivery of anticancer therapeutics. Nano Today 4, 302-317 (2009)

2 Jain, J. P., Yenet, A. W., Domb, A. J. \& Kumar, N. in Biodegradable Polymers in Clinical Use and Clinical Development (eds Domb A. J., Kumar N. \& Ezra A.) 1-58 (John Wiley \& Sons, Inc., Hoboken, NJ, 2011)

3 Van Vlierberghe, S., Dubruel, P. \& Schacht, E. Biopolymer-based hydrogels as scaffolds for tissue engineering applications: a review. Biomacromolecules 12, 1387-1408 (2011)

4 Knight, D. K., Gillies, E. R. \& Mequanint, K. Biomimetic I-aspartic acid-derived functional poly(ester amide)s for vascular tissue engineering. Acta Biomater. 10, 3484-3496 (2014).

5 Cheng, W., Yang, C., Ding, X., Engler, A. C., Hedrick, J. L. \& Yang, Y. Y. Broadspectrum antimicrobial/antifouling soft material coatings using poly(ethylenimine) as a tailorable scaffold. Biomacromolecules 16, 1967-1977 (2015).

6 Tsuji, H. in Biopolymers Vol. 4 (ed. Steinbüchel, A.) 129-178 (Wiley-VCH Verlag GmbH \& Co. KGaA, Weinheim, Germany, 2005).

7 Bat, E., Kothman, B. H. M., Higuera, G. A., van Blitterswijk, C. A., Feijen, J. \& Grijpma, D. W. Ultraviolet light crosslinking of poly(trimethylene carbonate) for elastomeric tissue engineering scaffolds. Biomaterials 31, 8696-8705 (2010).

8 Qu, X.-H., Wu, Q., Zhang, K.-Y. \& Chen, G. Q. In vivo studies of poly(3-hydroxybutyrate-co-3-hydroxyhexanoate) based polymers: biodegradation and tissue reactions. Biomaterials 27, 3540-3548 (2006).

9 Zhang, Z., Kuijer, R., Bulstra, S. K., Grijpma, D. W. \& Feijen, J. The in vivo and in vitro degradation behavior of poly(trimethylene carbonate). Biomaterials 27, 1741-1748 (2006).

10 Nair, L. S. \& Laurencin, C. T. Biodegradable polymers as biomaterials. Prog Polym Sci 32, 762-798 (2007).

11 Sisson, A. L., Schroeter, M. \& Lendlein, A. in Handbook of Biodegradable Polymers (eds Lendlein A. \& Sisson A.) 1-21 (Wiley-VCH Verlag GmbH \& Co. KGaA, Weinheim, Germany, 2011).

12 Zhang, C. in Biodegradable Polyesters (ed. Fakirov S.) 1-24 (Wiley-VCH Verlag GmbH \& Co. KGaA, Weinheim, Germany, 2015).

13 Tian, H., Tang, Z., Zhuang, X., Chen, X. \& Jing, X. Biodegradable synthetic polymers: Preparation, functionalization and biomedical application. Prog. Polym. Sci. 37, 237-280 (2012).

14 Suriano, F., Coulembier, O., Hedrick, J. L. \& Dubois, P. Functionalized cyclic carbonates: from synthesis and metal-free catalyzed ring-opening polymerization to applications. Polym. Chem. 2, 528-533 (2011).

$15 \mathrm{Xu}, \mathrm{J}$., Feng, E. \& Song, J. Renaissance of aliphatic polycarbonates: new techniques and biomedical applications. J. Appl. Polym. Sci. 131, 39822 (2014).

16 Dove, A. P., Pratt, R. C., Lohmeijer, B. G. G., Waymouth, R. M. \& Hedrick, J. L. Thiourea-based bifunctional organocatalysis: supramolecular recognition for living polymerization. J. Am. Chem. Soc. 127, 13798-13799 (2005).

17 Coady, D. J., Fukushima, K., Horn, H. W., Rice, J. E. \& Hedrick, J. L. New catalytic insights into acid/base conjugates: Highly selective bifunctional catalysts for ringopening polymerization. Chem. Commun. 47, 3105-3107 (2011).

18 Phipps, R. J., Hamilton, G. L. \& Toste, F. D. The progression of chiral anions from concepts to applications in asymmetric catalysis. Nat. Chem. 4, 603-614 (2012).

19 Akiyama, T. \& Mori, K. Stronger Brønsted acids: recent progress. Chem. Rev. 115 9277-9306 (2015).
20 Fukushima, K., Coulembier, O., Lecuyer, J. M., Almegren, H. A., Alabdulrahman, A. M., Alsewailem, F. D., McNeil, M. A., Dubois, P., Waymouth, R. M., Horn, H. W., Rice, J. E. \& Hedrick, J. L. Organocatalytic depolymerization of poly(ethylene terephthalate). J. Polym. Sci. A Polym. Chem. 49, 1273-1281 (2011).

21 Kamber, N. E., Tsujii, Y., Keets, K., Waymouth, R. M., Pratt, R. C., Nyce, G. W. \& Hedrick, J. L. The depolymerization of poly(ethylene terephthalate) (pet) using n-heterocyclic carbenes from ionic liquids. J. Chem. Educ. 87, 519-521 (2010).

22 Fukushima, K., Lecuyer, J. M., Wei, D. S., Horn, H. W., Jones, G. O., Al-Megren, H. A., Alabdulrahman, A. M., Alsewailem, F. D., McNeil, M. A. Rice, J. E. \& Hedrick, J. L. Advanced chemical recycling of poly(ethylene terephthalate) through organocatalytic aminolysis. Polym. Chem. 4, 1610-1616 (2013).

23 Fukushima, K., Liu, S., Wu, H., Engler, A. C., Coady, D. J., Maune, H., Pitera, J., Nelson, A., Wiradharma, N., Venkataraman, S., Huang, Y., Fan, W., Ying, J. Y., Yang, Y. Y. \& Hedrick, J. L. Supramolecular high-aspect ratio assemblies with strong antifungal activity. Nat. Commun. 4, 2861 (2013).

24 Fukushima, K., Tan, J. P. K., Korevaar, P. A., Yang, Y. Y., Pitera, J., Nelson, A., Maune, H., Coady, D. J., Frommer, J. E., Engler, A. C., Huang, Y., Xu, K., Ji, Z., Qiao, Y., Fan, W., Li, L., Wiradharma, N., Meijer, E. W. \& Hedrick, J. L. Broad-spectrum antimicrobial supramolecular assemblies with distinctive size and shape. ACS Nano 6, 9191-9199 (2012).

25 Fonseca, A. C., Gil, M. H. \& Simoes, P. N. Biodegradable poly(ester amide)s-a remarkable opportunity for the biomedical area: review on the synthesis, characterization and applications. Prog. Polym. Sci. 39, 1291-1311 (2014).

26 Rosario-Melendez, R., Yu, W. \& Uhrich, K. E. Biodegradable polyesters containing ibuprofen and naproxen as pendant groups. Biomacromolecules 14, 3542-3548 (2013).

27 Mizutani, M., Satoh, K. \& Kamigaito, M. Metal-catalyzed simultaneous chain- and step-growth radical polymerization: marriage of vinyl polymers and polyesters. J. Am. Chem. Soc. 132, 7498-7507 (2010).

28 Zhang, L. J., Dong, B. T., Du, F. S. \& Li, Z. C. Degradable thermoresponsive polyesters by atom transfer radical polyaddition and click chemistry. Macromolecules 45, 8580-8587 (2012).

29 Fokou, P. A. \& Meier, M. A. R. Use of a renewable and degradable monomer to study the temperature-dependent olefin isomerization during ADMET polymerizations. J. Am. Chem. Soc. 131, 1664-1665 (2009).

30 Shearouse, W. C., Lillie, L. M., Reineke, T. M. \& Tolman, W. B. Sustainable polyesters derived from glucose and castor oil: building block structure impacts properties. ACS Macro Lett. 4, 284-288 (2015).

31 Kimura, Y., Shirotani, K., Yamane, H. \& Kitao, T. Ring-opening polymerization of 3(s)-[(benzyloxycarbonyl)methyl]-1,4-dioxane-2,5-dione: a new route to a poly(.Alpha.hydroxy acid) with pendant carboxyl groups. Macromolecules 21, 3338-3340 (1988).

32 Pounder, R. J. \& Dove, A. P. Synthesis and organocatalytic ring-opening polymerization of cyclic esters derived from I-malic acid. Biomacromolecules 11, 1930-1939 (2010).

33 Gerhardt, W. W., Noga, D. E., Hardcastle, K. I., García, A. J., Collard, D. M. \& Weck, M. Functional lactide monomers: methodology and polymerization. Biomacromolecules 7, 1735-1742 (2006).

34 Leemhuis, M., van Nostrum, C. F., Kruijtzer, J. A. W., Zhong, Z. Y., ten Breteler, M. R., Dijkstra, P. J., Feijen, J. \& Hennink, W. E. Functionalized poly( $\alpha$-hydroxy acid)s via ring-opening polymerization: toward hydrophilic polyesters with pendant hydroxyl groups. Macromolecules 39, 3500-3508 (2006).

35 Nagahama, K., Imai, Y., Nakayama, T., Ohmura, J., Ouchi, T. \& Ohya, Y. Thermo-sensitive sol-gel transition of poly(depsipeptide-co-lactide)-g-peg copolymers in aqueous solution. Polymer 50, 3547-3555 (2009).

36 Xiao, H., Song, H., Yang, Q., Cai, H., Qi, R., Yan, L., Liu, S., Zheng, Y., Huang, Y., Liu, T. \& Jing, X. A prodrug strategy to deliver cisplatin(iv) and paclitaxel in nanomicelles to improve efficacy and tolerance. Biomaterials 33, 6507-6519 (2012).

37 Jiang, X., Vogel, E. B., Smith, M. R. \& Baker, G. L. 'Clickable' polyglycolides: tunable synthons for thermoresponsive, degradable polymers. Macromolecules 41, 1937-1944 (2008)

38 Truong, V., Blakey, I. \& Whittaker, A. K. Hydrophilic and amphiphilic polyethylene glycol-based hydrogels with tunable degradability prepared by 'click' chemistry. Biomacromolecules 13, 4012-4021 (2012).

39 Xing, D., Ma, L. \& Gao, C. Synthesis of functionalized poly(ester carbonate) with laminin-derived peptide for promoting neurite outgrowth of pc12 cells. Macromol. Biosci. 14, 1429-1436 (2014).

40 Onbulak, S., Tempelaar, S., Pounder, R. J., Gok, O., Sanyal, R., Dove, A. P. \& Sanyal, A. Synthesis and functionalization of thiol-reactive biodegradable polymers. Macromolecules 45, 1715-1722 (2012).

41 Williams, R. J., Barker, I. A., O'Reilly, R. K. \& Dove, A. P. Orthogonal modification of norbornene-functional degradable polymers. ACS Macro Lett. 1, 1285-1290 (2012).

42 Dag, A., Aydin, M., Durmaz, H., Hizal, G. \& Tunca, U. Various polycarbonate graft copolymers via diels-alder click reaction. J. Polym. Sci. A Polym. Chem. 50, 4476-4483 (2012)

43 Zhang, Z., Yin, L., Xu, Y., Tong, R., Lu, Y., Ren, J. \& Cheng, J. Facile functionalization of polyesters through thiol-yne chemistry for the design of degradable, cell-penetrating and gene delivery dual-functional agents. Biomacromolecules 13, 3456-3462 (2012).

44 Zou, J., Hew, C. C., Themistou, E., Li, Y., Chen, C.-K., Alexandridis, P. \& Cheng, C. Clicking well-defined biodegradable nanoparticles and nanocapsules by uv-induced thiol-ene cross-linking in transparent miniemulsions. Adv. Mater. 23, 4274-4277 (2011). 
45 Yu, Y., Zou, J. \& Cheng, C. Synthesis and biomedical applications of functional poly ([small alpha]-hydroxyl acid)s. Polym. Chem. 5, 5854-5872 (2014).

46 Martin Vaca, B. \& Bourissou, D. O-carboxyanhydrides: useful tools for the preparation of well-defined functionalized polyesters. ACS Macro Lett. 4, 792-798 (2015).

47 Barrera, D. A., Zylstra, E., Lansbury, P. T. \& Langer, R. Synthesis and rgd peptide modification of a new biodegradable copolymer: poly(lactic acid-co-lysine). J. Am Chem. Soc. 115, 11010-11011 (1993).

48 Deming, T. J. Synthetic polypeptides for biomedical applications. Prog. Polym. Sci. 32, 858-875 (2007).

49 Yu, M., Nowak, A. P., Deming, T. J. \& Pochan, D. J. Methylated mono- and diethyleneglycol functionalized polylysines: nonionic, $\alpha$-helical, water-soluble polypeptides. J Am. Chem. Soc. 121, 12210-12211 (1999).

50 Deming, T. J. Synthesis of side-chain modified polypeptides. Chem. Rev. 116, 786-808 (2016).

51 Jaffredo, C. G. \& Guillaume, S. M. Benzyl $\beta$-malolactonate polymers: a long story with recent advances. Polym. Chem. 5, 4168-4194 (2014).

52 Trollsås, M., Lee, V. Y., Mecerreyes, D., Löwenhielm, P., Möller, M., Miller, R. D. \& Hedrick, J. L. Hydrophilic aliphatic polyesters: design, synthesis, and ring-opening polymerization of functional cyclic esters. Macromolecules 33, 4619-4627 (2000).

53 Hao, J., Cheng, Y., Ranatunga, R.J.K.U., Senevirathne, S., Biewer, M. C., Nielsen, S. O., Wang, Q. \& Stefan, M. C. A combined experimental and computational study of the substituent effect on micellar behavior of $\gamma$-substituted thermoresponsive amphiphilic poly(e-caprolactone)s. Macromolecules 46, 4829-4838 (2013).

54 Thillaye du Boullay, O., Bonduelle, C., Martin-Vaca, B. \& Bourissou, D. Functionalized polyesters from organocatalyzed rop of gluoca, the o-carboxyanhydride derived from glutamic acid. Chem Commun 15, 1786-1788 (2008).

55 Yin, Q., Yin, L., Wang, H. \& Cheng, J. Synthesis and biomedical applications of functional poly( $\alpha$-hydroxy acids) via ring-opening polymerization of o-carboxyanhydrides. Acc Chem. Res. 48, 1777-1787 (2015).

$56 \mathrm{Hu}, \mathrm{X}$., Chen, X., Cheng, H. \& Jing, X. Cinnamate-functionalized poly(ester-carbonate): synthesis and its uv irradiation-induced photo-crosslinking. J. Polym. Sci. A Polym. Chem. 47, 161-169 (2009).

57 Ajiro, H., Takahashi, Y. \& Akashi, M. Thermosensitive biodegradable homopolymer of trimethylene carbonate derivative at body temperature. Macromolecules 45, 2668-2674 (2012)

58 Zhang, X., Cai, M., Zhong, Z. \& Zhuo, R. A water-soluble polycarbonate with dimethylamino pendant groups prepared by enzyme-catalyzed ring-opening polymerization. Macromol. Rapid Commun. 33, 693-697 (2012).

59 Venkataraman, S., Veronica, N., Voo, Z. X., Hedrick, J. L. \& Yang, Y. Y. 2-amino-1,3propane diols: a versatile platform for the synthesis of aliphatic cyclic carbonate monomers. Polym. Chem. 4, 2945-2948 (2013).

60 Weilandt, K. D., Keul, H. \& Höcker, H. Synthesis and ring-opening polymerization of 2-acetoxymethyl-2-alkyltrimethylene carbonates and of 2-methoxycarbonyl-2methyltrimethylene carbonate; a comparison with the polymerization of 2,2-dimethyltrimethylene carbonate. Macromol. Chem. Phys. 197, 3851-3868 (1996).

61 Ihre, H., Hult, A. \& Söderlind, E. Synthesis, characterization, and $1 \mathrm{~h}$ nmr selfdiffusion studies of dendritic aliphatic polyesters based on 2,2-bis(hydroxymethyl) propionic acid and 1,1,1-tris(hydroxyphenyl)ethane. J. Am. Chem. Soc. 118, 6388-6395 (1996).

62 Al-Azemi, T. F. \& Bisht, K. S. Novel functional polycarbonate by lipase-catalyzed ringopening polymerization of 5-methyl-5-benzyloxycarbonyl-1,3-dioxan-2-one. Macromolecules 32, 6536-6540 (1999).

63 Mullen, B. D., Tang, C. N. \& Storey, R. F. New aliphatic poly(ester-carbonates) based on 5-methyl-5-allyloxycarbonyl-1,3-dioxan-2-one. J. Polym. Sci. A Polym. Chem. 41, 1978-1991 (2003).

64 Pratt, R. C., Nederberg, F., Waymouth, R. M. \& Hedrick, J. L. Tagging alcohols with cyclic carbonate: a versatile equivalent of (meth)acrylate for ring-opening polymerization. Chem. Commun. 1, 114-116 (2008).

65 Sanders, D. P., Fukushima, K., Coady, D. J., Nelson, A., Fujiwara, M., Yasumoto, M. \& Hedrick, J. L. A simple and efficient synthesis of functionalized cyclic carbonate monomers using a versatile pentafluorophenyl ester intermediate. J. Am. Chem. Soc. 132, 14724-14726 (2010).

66 Eberhardt, M. \& Théato, P. Raft polymerization of pentafluorophenyl methacrylate: Preparation of reactive linear diblock copolymers. Macromol. Rapid Commun. 26, 1488-1493 (2005).

67 Fukushima, K., Kishi, K., Takaoka, S., Inoue, Y., Sato, C. \& Tanaka, M. Facile and practical route to a versatile intermediate of substituted cyclic carbonates offering diverse smart biomaterials. Abstr. Pap. Am. Chem. Soc. 248, POLY-68 (2014).

68 JP2014227412A, Tanaka, M., Fukushima, K., Inoue, Y., Sato, C. \& Sasaki, A. Method of producing cylcic carbonate (2014).

69 Fukushima, K. Poly(trimethylene carbonate)-based polymers engineered for biodegradable functional biomaterials. Biomater. Sci. 4, 9-24 (2016).

70 Hawker, C. J. \& Russell, T. P. Block copolymer lithography: merging 'bottom-up' with 'top-down' processes. MRS Bull. 30, 952-966 (2005).

71 Kamber, N. E., Jeong, W., Waymouth, R. M., Pratt, R. C., Lohmeijer, B. G. G. \& Hedrick, J. L. Organocatalytic ring-opening polymerization. Chem. Rev. 107, 5813-5840 (2007).

72 Kiesewetter, M. K., Shin, E. J., Hedrick, J. L. \& Waymouth, R. M. Organocatalysis: Opportunities and challenges for polymer synthesis. Macromolecules 43, 2093-2107 (2010).

73 Dechy-Cabaret, O., Martin-Vaca, B. \& Bourissou, D. Controlled ring-opening polymerization of lactide and glycolide. Chem. Rev. 104, 6147-6176 (2004).
74 Kowalski, A., Duda, A. \& Penczek, S. Polymerization of I,I-lactide initiated by aluminum isopropoxide trimer or tetramer. Macromolecules 31, 2114-2122 (1998).

75 Ovitt, T. M. \& Coates, G. W. Stereoselective ring-opening polymerization of rac-lactide with a single-site, racemic aluminum alkoxide catalyst: synthesis of stereoblock poly (lactic acid). J. Polym. Sci. A Polym. Chem. 38, 4686-4692 (2000).

76 Spassky, N., Wisniewski, M., Pluta, C. \& Le Borgne, A. Highly stereoelective polymerization of rac-(d,I)-lactide with a chiral schiff's base/aluminium alkoxide initiator. Macromol. Chem. Phys. 197, 2627-2637 (1996).

77 Nachtergael, A., Coulembier, O., Dubois, P., Helvenstein, M., Duez, P., Blankert, B. \& Mespouille, L. Organocatalysis paradigm revisited: are metal-free catalysts really harmless? Biomacromolecules 16, 507-514 (2015).

78 Dove, A. P. Controlled ring-opening polymerisation of cyclic esters: polymer blocks in self-assembled nanostructures. Chem. Commun. 48, 6446-6470 (2008).

79 Dove, A. P. Organic catalysis for ring-opening polymerization. ACS Macro Lett. 1, 1409-1412 (2012)

80 Delcroix, D., Couffin, A., Susperregui, N., Navarro, C., Maron, L., Martin-Vaca, B. \& Bourissou, D. Phosphoric and phosphoramidic acids as bifunctional catalysts for the ring-opening polymerization of $\varepsilon$-caprolactone: a combined experimental and theoretical study. Polym. Chem. 2, 2249-2256 (2011).

81 Gazeau-Bureau, S., Delcroix, D., Martín-Vaca, B., Bourissou, D., Navarro, C. \& Magnet, S. Organo-catalyzed rop of $\epsilon$-caprolactone: methanesulfonic acid competes with trifluoromethanesulfonic acid. Macromolecules 41, 3782-3784 (2008).

82 Coady, D. J., Horn, H. W., Jones, G. O., Sardon, H., Engler, A. C., Waymouth, R. M., Rice, J. E., Yang, Y. Y. \& Hedrick, J. L. Polymerizing base sensitive cyclic carbonates using acid catalysis. ACS Macro Lett. 2, 306-312 (2013).

83 Magill, A. M., Cavell, K. J. \& Yates, B. F. Basicity of nucleophilic carbenes in aqueous and nonaqueous solvents theoretical predictions. J. Am. Chem. Soc. 126, 8717-8724 (2004).

84 Kaljurand, I., Kütt, A., Sooväli, L., Rodima, T., Mäemets, V., Leito, I. \& Koppel, I. A. Extension of the self-consistent spectrophotometric basicity scale in acetonitrile to a full span of 28 pka units: unification of different basicity scales. J. Org. Chem. 70, 1019-1028 (2005)

85 Pratt, R. C., Lohmeijer, B. G. G., Long, D. A., Waymouth, R. M. \& Hedrick, J. L. Triazabicyclodecene: a simple bifunctional organocatalyst for acyl transfer and ring-opening polymerization of cyclic esters. J. Am. Chem. Soc. 128, 4556-4557 (2006).

86 Connor, E. F., Nyce, G. W., Myers, M., Möck, A. \& Hedrick, J. L. First example of $\mathrm{n}$-heterocyclic carbenes as catalysts for living polymerization: organocatalytic ring-opening polymerization of cyclic esters. J. Am. Chem. Soc. 124, 914-915 (2002).

87 Fukushima, K., Coady, D. J., Jones, G. O., Almegren, H. A., Alabdulrahman, A. M., Alsewailem, F. D., Horn, H. W., Rice, J. E. \& Hedrick, J. L. Unexpected efficiency of cyclic amidine catalysts in depolymerizing poly(ethylene terephthalate). J. Polym. Sci. A Polym. Chem. 51, 1606-1611 (2013).

88 Nyce, G. W., Lamboy, J. A., Connor, E. F., Waymouth, R. M. \& Hedrick, J. L. Expanding the catalytic activity of nucleophilic n-heterocyclic carbenes for transesterification reactions. Org. Lett. 4, 3587-3590 (2002).

89 Coulembier, O., Kiesewetter, M. K., Mason, A., Dubois, P., Hedrick, J. L. \& Waymouth, R. M. A distinctive organocatalytic approach to complex macromolecular architectures. Angew. Chem. Int. Ed. 46, 4719-4721 (2007).

90 Coady, D. J., Engler, A. C., Yang, Y. Y. \& Hedrick, J. L. Facile routes to star polymers via an organocatalytic approach. Polym. Chem. 2, 2619-2626 (2011).

91 Lohmeijer, B. G. G., Pratt, R. C., Leibfarth, F., Logan, J. W., Long, D. A., Dove, A. P., Nederberg, F., Choi, J., Wade, C., Waymouth, R. M. \& Hedrick, J. L. Guanidine and amidine organocatalysts for ring-opening polymerization of cyclic esters. Macromolecules 39, 8574-8583 (2006).

92 Coulembier, O., Sanders, D. P., Nelson, A., Hollenbeck, A. N., Horn, H. W., Rice, J. E., Fujiwara, M., Dubois, P. \& Hedrick, J. L. Hydrogen-bonding catalysts based on fluorinated alcohol derivatives for living polymerization. Angew. Chem. Int. Ed. 48, 5170-5173 (2009).

93 Nederberg, F., Lohmeijer, B. G. G., Leibfarth, F., Pratt, R. C., Choi, J., Dove, A. P., Waymouth, R. M. \& Hedrick, J. L. Organocatalytic ring opening polymerization of trimethylene carbonate. Biomacromolecules 8, 153-160 (2007).

94 Chuma, A., Horn, H. W., Swope, W. C., Pratt, R. C., Zhang, L., Lohmeijer, B. G. G., Wade, C. G., Waymouth, R. M., Hedrick, J. L. \& Rice, J. E. The reaction mechanism for the organocatalytic ring-opening polymerization of I-lactide using a guanidinebased catalyst: Hydrogen-bonded or covalently bound?. J. Am. Chem. Soc. 130, 6749-6754 (2008).

95 Kano, T., Aota, Y., Asakawa, D. \& Maruoka, K. Bronsted acid-catalyzed mannich reaction through dual activation of aldehydes and n-boc-imines. Chem. Commun. 51, 16472-16474 (2015).

96 Sardon, H., Chan, J. M. W., Ono, R. J., Mecerreyes, D. \& Hedrick, J. L. Highly tunable polyurethanes: organocatalyzed polyaddition and subsequent post-polymerization modification of pentafluorophenyl ester sidechains. Polym. Chem. 5, 3547-3550 (2014).

97 Sardon, H., Engler, A. C., Chan, J. M. W., Garcia, J. M., Coady, D. J., Pascual, A., Mecerreyes, D., Jones, G. O., Rice, J. E., Horn, H. W. \& Hedrick, J. L. Organic acidcatalyzed polyurethane formation via a dual-activated mechanism: unexpected preference of n-activation over 0-activation of isocyanates. J. Am. Chem. Soc. 135, 16235-16241 (2013). 
98 Sardon, H., Pascual, A., Mecerreyes, D., Taton, D., Cramail, H. \& Hedrick, J. L. Synthesis of polyurethanes using organocatalysis: a perspective. Macromolecules $\mathbf{4 8}$ 3153-3165 (2015)

99 Chitkara, D., Mittal, A., Behrman, S. W., Kumar, N. \& Mahato, R. I. Self-assembling, amphiphilic polymer-gemcitabine conjugate shows enhanced antitumor efficacy against human pancreatic adenocarcinoma. Bioconjug. Chem. 24, 1161-1173 (2013).

100 Lee, A. L. Z., Ng, V. W. L., Gao, S. J., Hedrick, J. L. \& Yang, Y. Y. Injectable hydrogels from triblock copolymers of vitamin e- functionalized polycarbonate and poly(ethylene glycol) for subcutaneous delivery of antibodies for cancer therapy. Adv. Funct. Mater. 24, 1538-1550 (2014)

101 Chin, W., Yang, C., Ng, V. W. L., Huang, Y., Cheng, J., Tong, Y. W., Coady, D. J., Fan, W., Hedrick, J. L. \& Yang, Y. Y. Biodegradable broad-spectrum antimicrobial polycarbonates: Investigating the role of chemical structure on activity and selectivity. Macromolecules 46, 8797-8807 (2013).

102 Engler, A. C., Tan, J. P. K., Ong, Z. Y., Coady, D. J., Ng, V. W. L., Yang, Y. Y. \& Hedrick, J. L. Antimicrobial polycarbonates: investigating the impact of balancing charge and hydrophobicity using a same-centered polymer approach. Biomacromolecules 14, 4331-4339 (2013).

103 Suriano, F., Pratt, R., Tan, J. P. K., Wiradharma, N., Nelson, A., Yang, Y. Y., Dubois, P. \& Hedrick, J. L. Synthesis of a family of amphiphilic glycopolymers via controlled ring-opening polymerization of functionalized cyclic carbonates and their application in drug delivery. Biomaterials 31, 2637-2645 (2010).

104 Cooley, C. B., Trantow, B. M., Nederberg, F., Kiesewetter, M. K., Hedrick, J. L. Waymouth, R. M. \& Wender, P. A. Oligocarbonate molecular transporters: oligomerization-based syntheses and cell-penetrating studies. J. Am. Chem. Soc. 131, 16401-16403 (2009).

105 Geihe, E. I., Cooley, C. B., Simon, J. R., Kiesewetter, M. K., Edward, J. A., Hickerson, R. P., Kaspar, R. L., Hedrick, J. L., Waymouth, R. M. \& Wender, P. A Designed guanidinium-rich amphipathic oligocarbonate molecular transporters complex, deliver and release sirna in cells. Proc. Natl. Acad. Sci. USA 109 13171-13176 (2012).

106 Aguirre-Chagala, Y. E., Santos, J. L., Aguilar-Castillo, B. A. \& Herrera-Alonso, M Synthesis of copolymers from phenylboronic acid-installed cyclic carbonates. ACS Macro Lett. 3, 353-358 (2014).

107 Langer, R. \& Peppas, N. A. Advances in biomaterials, drug delivery, and bionanotechnology. AlChE J. 49, 2990-3006 (2003).

108 Tsuji, H. Poly(lactide) stereocomplexes: formation, structure, properties, degradation, and applications. Macromol. Biosci. 5, 569-597 (2005).

109 Fukushima, K. \& Kimura, Y. Stereocomplexed polylactides (neo-pla) as high-performance bio-based polymers: Their formation, properties, and application. Polym. Int. 55, 626-642 (2006)

110 Nederberg, F., Appel, E., Tan, J. P. K., Kim, S. H., Fukushima, K., Sly, J., Miller, R. D., Waymouth, R. M., Yang, Y. Y. \& Hedrick, J. L. Simple approach to stabilized micelles employing miktoarm terpolymers and stereocomplexes with application in paclitaxel delivery. Biomacromolecules 10, 1460-1468 (2009).

111 Fukushima, K., Pratt, R. C., Nederberg, F., Tan, J. P. K., Yang, Y. Y., Waymouth, R. M. \& Hedrick, J. L. Organocatalytic approach to amphiphilic comb-block copolymers capable of stereocomplexation and self-assembly. Biomacromolecules 9, 3051-3056 (2008).

112 Kim, S. H., Tan, J. P. K., Nederberg, F., Fukushima, K., Colson, J., Yang, C. Nelson, A., Yang, Y. Y. \& Hedrick, J. L. Hydrogen bonding-enhanced micelle assemblies for drug delivery. Biomaterials 31, 8063-8071 (2010).

113 Tan, J. P. K., Kim, S. H., Nederberg, F., Fukushima, K., Coady, D. J., Nelson, A., Yang, Y. Y. \& Hedrick, J. L. Delivery of anticancer drugs using polymeric micelles stabilized by hydrogen-bonding urea groups. Macromol. Rapid Commun. 31, 1187-1192 (2010)

114 Ke, X. Y., Ng, V. W. L., Gao, S. J., Tong, Y. W., Hedrick, J. L. \& Yang, Y. Y. Co-delivery of thioridazine and doxorubicin using polymeric micelles for targeting both cancer cells and cancer stem cells. Biomaterials 35, 1096-1108 (2014).

115 Ebrahim Attia, A. B., Yang, C., Tan, J. P. K., Gao, S., Williams, D. F., Hedrick, J. L. \& Yang, Y. Y. The effect of kinetic stability on biodistribution and anti-tumor efficacy of drug-loaded biodegradable polymeric micelles. Biomaterials 34, 3132-3140 (2013).

116 Yang, C., Attia, A. B. E., Tan, J. P. K., Ke, X. Y., Gao, S. J., Hedrick, J. L. \& Yang, Y. Y. The role of non-covalent interactions in anticancer drug loading and kinetic stability of polymeric micelles. Biomaterials 33, 2971-2979 (2012).

117 Palermo, E. \& Kuroda, K. Structural determinants of antimicrobial activity in polymers which mimic host defense peptides. Appl. Microbiol. Biotechnol. 87, 1605-1615 (2010).

118 Kenawy, E.-R., Worley, S. D. \& Broughton, R. The chemistry and applications of antimicrobial polymers: A state-of-the-art review. Biomacromolecules 8, 1359-1384 (2007).

119 Pack, D. W., Hoffman, A. S., Pun, S. \& Stayton, P. S. Design and development of polymers for gene delivery. Nat. Rev. Drug Discov. 4, 581-593 (2005)

120 Nederberg, F., Zhang, Y., Tan, J. P. K., Xu, K. J., Wang, H. Y., Yang, C., Gao, S. Guo, X. D., Fukushima, K., Li, L., Hedrick, J. L. \& Yang, Y. Y. Biodegradable nanostructures with selective lysis of microbial membranes. Nat. Chem. 3, 409-414 (2011)

121 Ong, Z. Y., Fukushima, K., Coady, D. J., Yang, Y.-Y., Ee, P. L. R. \& Hedrick, J. L. Rational design of biodegradable cationic polycarbonates for gene delivery. J. Controlled Release 152, 120-126 (2011).
122 Hancock, R. E. W. \& Sahl, H.-G. Antimicrobial and host-defense peptides as new antiinfective therapeutic strategies. Nat. Biotechnol. 24, 1551-1557 (2006)

123 Qiao, Y., Yang, C., Coady, D. J., Ong, Z. Y., Hedrick, J. L. \& Yang, Y.-Y. Highly dynamic biodegradable micelles capable of lysing gram-positive and gram-negative bacterial membrane. Biomaterials 33, 1146-1153 (2012).

124 Tanaka, M., Fukushima, K., Sato, C., Sasaki, A. \& Kishi, K. Antibacterial polymer, production method therefor, and usage thereof 2015.

125 Akinc, A., Thomas, M., Klibanov, A. M. \& Langer, R. Exploring polyethyleniminemediated DNA transfection and the proton sponge hypothesis. J. Gene Med. 7, 657-663 (2005)

126 Zhang, Y., Yin, Q., Yin, L., Ma, L., Tang, L. \& Cheng, J. Chain-shattering polymeric therapeutics with on-demand drug-release capability. Angew. Chem. Int. Ed. 52, 6435-6439 (2013).

127 Cheng, R., Meng, F., Deng, C., Klok, H.-A. \& Zhong, Z. Dual and multi-stimul responsive polymeric nanoparticles for programmed site-specific drug delivery. Biomaterials 34, 3647-3657 (2013).

128 Moon, H. J., Ko, D. Y., Park, M. H., Joo, M. K. \& Jeong, B. Temperature-responsive compounds as in situ gelling biomedical materials. Chem. Soc. Rev. 41, 4860-4883 (2012)

129 Yu, Y., Chen, C.-K., Law, W.-C., Weinheimer, E., Sengupta, S., Prasad, P. N. \& Cheng, C. Polylactide-graft-doxorubicin nanoparticles with precisely controlled drug loading for ph-triggered drug delivery. Biomacromolecules 15, 524-532 (2014).

130 Wang, M., Sun, J., Zhai, Y., Lian, H., Luo, C., Li, L., Du, Y., Zhang, D., Ding, W., Qiu, S., Liu, Y., Kou, L., Han, X., Xiang, R., Wang, Y. \& He, Z. Enteric polymer based on ph-responsive aliphatic polycarbonate functionalized with vitamin e to facilitate oral delivery of tacrolimus. Biomacromolecules 16, 1179-1190 (2015).

131 Hu, D., Peng, H., Niu, Y., Li, Y., Xia, Y., Li, L., He, J.,Liu, X., Xia, X., Lu, Y. \& Xu, W. Reversibly light-responsive biodegradable poly(carbonate) micelles constructed via cuaac reaction. J. Polym. Sci. A Polym. Chem. 53, 750-760 (2015).

132 Roy, D. \& Sumerlin, B. S. Glucose-sensitivity of boronic acid block copolymers at physiological ph. ACS Macro Lett. 1, 529-532 (2012).

133 Lutz, J.-F., Andrieu, J., Üzgün, S., Rudolph, C. \& Agarwal, S. Biocompatible, thermoresponsive, and biodegradable: simple preparation of 'all-in-one' biorelevant polymers. Macromolecules 40, 8540-8543 (2007).

134 Lutz, J.-F., Akdemir, Ö. \& Hoth, A. Point by point comparison of two thermosensitive polymers exhibiting a similar lcst: is the age of poly(nipam) over? J. Am. Chem. Soc. 128, 13046-13047 (2006).

135 Jiang, X., Smith, M. R. \& Baker, G. L. Water-soluble thermoresponsive polylactides. Macromolecules 41, 318-324 (2008).

136 Kim, S. H., Tan, J. P. K., Fukushima, K., Nederberg, F., Yang, Y. Y., Waymouth, R. M. \& Hedrick, J. L. Thermoresponsive nanostructured polycarbonate block copolymers as biodegradable therapeutic delivery carriers. Biomaterials 32, 5505-5514 (2011).

137 Fujiwara, T., Mukose, T., Yamaoka, T., Yamane, H., Sakurai, S. \& Kimura, Y. Novel thermo-responsive formation of a hydrogel by stereo-complexation between plla-peg-plla and pdla-peg-pdla block copolymers. Macromol. Biosci. 1, 204-208 (2001)

138 Li, Y., Fukushima, K., Coady, D. J., Engler, A. C., Liu, S., Huang, Y., Cho, J. S., Guo, Y., Miller, L. S., Tan, J. P., Ee, P. L., Fan, W., Yang, Y. Y. \& Hedrick, J. L. Broad-spectrum antimicrobial and biofilm-disrupting hydrogels: stereocomplex-driven supramolecular assemblies. Angew Chem. Int. Ed. 52, 674-678 (2013).

139 Chen, W., Zou, Y., Jia, J., Meng, F., Cheng, R., Deng, C., Feijen, J. \& Zhong, Z. Functional poly( $\varepsilon$-caprolactone)s via copolymerization of $\varepsilon$-caprolactone and pyridy disulfide-containing cyclic carbonate: controlled synthesis and facile access to reduction-sensitive biodegradable graft copolymer micelles. Macromolecules 46 , 699-707 (2013).

140 Engler, A. C., Chan, J. M. W., Fukushima, K., Coady, D. J., Yang, Y. Y. \& Hedrick, J. L. Polycarbonate-based brush polymers with detachable disulfide-linked side chains. ACS Macro Lett. 2, 332-336 (2013).

141 Engler, A. C., Wiradharma, N., Ong, Z. Y., Coady, D. J., Hedrick, J. L. \& Yang, Y.-Y. Emerging trends in macromolecular antimicrobials to fight multi-drug-resistant infections. Nano Today 7, 201-222 (2012).

142 Venkataraman, S., Hedrick, J. L., Ong, Z. Y., Yang, C., Ee, P. L. R., Hammond, P. T. \& Yang, Y. Y. The effects of polymeric nanostructure shape on drug delivery. Adv. Drug Del. Rev. 63, 1228-1246 (2011).

143 Kim, S. H., Nederberg, F., Jakobs, R., Tan, J. P. K., Fukushima, K., Nelson, A. Meijer, E. W., Yang, Y. Y. \& Hedrick, J. L. A supramolecularly assisted transformation of block-copolymer micelles into nanotubes. Angew. Chem. Int. Ed. 48, 4508-4512 (2009)

144 Tanaka, M., Sato, K., Kitakami, E., Kobayashi, S., Hoshiba, T. \& Fukushima, K. Design of biocompatible and biodegradable polymers based on intermediate water concept. Polym. J. 47, 114-121 (2015).

145 Fukushima, K., Tsai, M.-Y., Ota, T., Haga, Y., Matsuzaki, K., Inoue, Y. \& Tanaka, M. Evaluation of the hemocompatibility of hydrated biodegradable aliphatic carbonyl polymers with a subtle difference in the backbone structure based on the intermediate water concept and surface hydration. Polym. J. 47, 469-473 (2015).

146 Fukushima, K., Inoue, Y. \& Tanaka, M. Antithrombotic biodegradable polycarbonates for regenerative medicines. Abstr. Pap. Am. Chem. Soc. 246, POLY-157 (2013).

147 Tanaka, M., Fukushima, K., Sato, C., Sasaki, A. \& Inoue, Y. Biocompatible polymer as antithrombogenic material, cyclic carbonate useful as precursor thereof, and method for producing same. Patent WO2014133102A. (2014). 


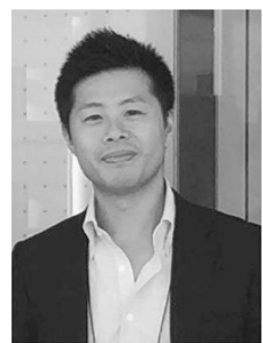

Dr Kazuki Fukushima was born in Hyogo Prefecture, Japan in 1980. He received his $\mathrm{PhD}$ in 2007 from Kyoto Institute of Technology under the supervision of Prof. Yoshiharu Kimura. During his research fellowship (DC2/PD, 04/2006-03/2008) of Japan Society for the Promotion of Science, he started postdoctoral career at IBM Almaden Research Center in San Jose, California under the co-supervision of Prof. Robert M. Waymouth of Stanford University and Dr James L. Hedrick of IBM from 2007, subsequently being hired by IBM as a postdoctoral researcher in 2009. In 2011, he was appointed as an Assistant Professor of Yamagata University. He has received the 1st GSC Student Travel Grant Award from the Japan Association for Chemical Innovation (2005), the Award for Encouragement of Research in Polymer Science, The Society of Polymer Science, Japan (2015), and the Chemical Society of Japan Presentation Award for Industries (2016). His current research focuses on the synthesis and biomedical applications of functionalized biodegradable polymers, in combination with supramolecular self-assembly. 